\title{
EXPERIMENTAL INVESTIGATION OF MIXED MODE I/II BRITTLE FRACTURE THAT USES ASYMMETRIC-SEMI CIRCULAR BEND SPECIMEN
}

\author{
Shridharmurthy $\mathbf{H ~ N}^{\mathbf{1}}$, H K Srinivas ${ }^{2}$, Shashidhara L $\mathrm{C}^{3}$, Madhusudhan $\mathrm{T}^{\mathbf{4}}$ \\ ${ }^{I}$ M.Tech Student: dept. of Mechanical Engineering, SJBIT (VTU), Bengaluru, India-560060 \\ ${ }^{2}$ Professor: dept. of Mechanical Engineering, SJBIT (VTU), Bengaluru, India-560060 \\ ${ }^{3}$ Professor: dept. of Mechanical Engineering, Dayanand Sagar University, Bengaluru, India-560038 \\ ${ }^{4}$ Head: dept. of Mechanical Engineering, SJBIT (VTU), Bengaluru, India-560060
}

\begin{abstract}
Asymmetric semi circular bend specimen (ASCB) is employed in this work for investigating brittle fracture of mixed mode (mode I/II combination). Epoxy resin is chosen as specimen material for brittle fracture study. By varying support locations (S2 location), pure mode I, pure mode II and different mode mixities are obtained. The specimens are prepared by molding epoxy resin with hardener. Later machining of specimens is done to achieve semicircular shape. Cracks are introduced by using tool end cutter machine. Crack growth directions and fracture load and crosshead movement are found out after carrying out mixed mode tests on Universal Testing Machine. The results are reported.
\end{abstract}

Keywords-ASCB specimen; Mixed mode; Universal Testing Machine; fracture load; Displacement. $* * *$

\section{INTRODUCTION}

In engineering components and structures cracks are inevitable in most of the situations. They can be formed during manufacturing, handling, due to environmental causes or due to repetitive loads, etc. Fracture is nothing but unstable development of crack resulting in failure of component in turn machine breakdown. When load is applied, the cracks, which are present earlier, results in fracture. Thus For a cracked component, in presence of in-plane loading, pure mode I or pure mode II fracture takes place. In practical situations most commonly the components are subjected to mixed mode I / I fracture i.e combination of mode I mode II .

In order to prevent catastrophic failure of components and structures studies have to be carried out on causes of failure like mixed mode failure. By finding out direction of crack propagation and fracture load, the necessary control action can be taken in order to avoid it in future, in corresponding applications. Many research works have been carried out using different test specimens and different techniques. The most popular brittle materials of interest for mixed mode fracture were mainly rocks [9], [10], [12], [14], [15], ceramics [5], [8], [20], [21], Glasses like plexiglass (PMMA) [2], [3], [7], [11], [15], [16], soda lime silica glass [4], [6], [7], [13], [17], [18], [19] and some polymers.

The mixed mode (mode I and mode II) fracture toughness found out experimentally using many types of methods and specimens. Indentation technique used are Knoop indentation tests [4], [6] and Vickers indentation tests [8], [13]. The popular test methods used for experiments include cracked
Brazilian disc [10], [11], [12], [14], [19], [21] under diametrical compression and semicircular bend specimen [9], [12], [15], [16], [20] with thru crack under three point bending. From the literature it can be concluded that the simplicity of loading fixture, manufacturing ease and specimen pre-cracking were prime reasons for selecting specimens and testing procedure for particular mixed mode testing in brittle material [15]. The testing method chosen should be such that the full range of loading conditions for mixed mode starting from pure mode I to pure mode II and wide variety of these two modes combinations should be possible.

The practical experiments were approximated using several theoretical criteria. Most famous criteria used for mixed mode fracture criterion are:- maximum tangential stress criterion [4], maximum energy release rate criterion [2], strain energy density criterion [3]. Some of the researchers derived the empirical equation which closely approximated experimental results for brittle fracture in mixed mode. Generalized or modified maximum tangential stress criterion (GMTS) [1], [15], [16], [19], [20], [21] used in many research works which takes into account T-stress. In cracked Brazilian disc specimen negative T-stresses [19] would be present which enhances fracture resistance in CBD. In semicircular bend (SCB) specimen positive T-stresses would be present which reduces fracture resistance [20].

As suggested by M. R. Ayatollahi et al. (2011) [1] Asymmetric semi circular bend specimen (ASCB) is employed in this work for investigating brittle fracture of mixed mode (Mode I / II combination). Epoxy resin is 
chosen as specimen material for brittle fracture study. By varying support locations (S2 location), pure mode I, pure mode II and different mode mixities are obtained. Cracks are introduced by using tool and cutter machine. Specimen manufacturing, crack introduction, asymmetric three point bending test on Universal Testing machine is explained further. Results are reported.

\section{CHOICE OF MATERIAL AND MOLD PREPARATION}

\subsection{Material Selection}

Epoxy resin is chosen as the specimen brittle material for the present work. Epoxy resin sheets of thickness $6 \mathrm{~mm}$ is prepared by using Perspex mold. The K-6 hardener is mixed with Lapox C-51 resin in the ratio 1:10 to prepare Epoxy resin solution which is then poured into the mold followed by curing in order to prepare Epoxy sheet. It is then machined to get desired specimen shape. It has Poissons ratio $(v)-0.33$ Young's Modulus ( E ) - 3 GPa [22].

\subsection{Mold Preparation}

Epoxy resin sheets of thickness $6 \mathrm{~mm}$ is prepared by using Perspex mold. $1 \mathrm{~kg}$ resin is poured in a beaker by side wall of beaker in order to avoid bubbles. The creation of bubbles in large quantity leads in spoilt resin. So, enormous care is taken so that only minimum bubbles are formed during pouring resin into beaker. The resin is kept in beaker for 24 hours in order to make bubbles disappear. The bubbleless resin after 24 hours is shown in Fig. 1. The mold consists of following components-

a) Perspex sheets: Perspex is also called as Acrylic glass or Polymethylmethacrylate (PMMA). These 2 sheets kept at a distance $6 \mathrm{~mm}$ by using spacers. Perspex sheets are shown in Fig. 2.

b) Aluminium spacers: 3 aluminium spacers of thickness $6 \mathrm{~mm}$ are placed at 3 sides between Perspex sheets. Aluminium spacers are shown in Fig. 3. Aluminium spacers between Perspex sheets are fitted with bolts and nuts for mold assembly. Perspex mold is shown in Fig 4.

The K-6 hardener is mixed with Lapox C-51 resin in the ratio 1:10 to prepare Epoxy resin solution. $100 \mathrm{~g}$ of hardener is mixed with $1 \mathrm{~kg}$ of resin. The hardener is poured into the beaker with bubbleless resin which is prepared earlier. The hardener is added from the wall of beaker slowly again to avoid formation of bubbles. Then a glass rod is used to stir the mixture in beaker in order to make the mixture homogeneous. The stirring had to be carried out for a period of 30 minutes. This process is exothermic reaction. After stirring it becomes homogeneous solution with light pale yellow colour.

After preparing homogeneous epoxy solution, it is poured into the mold slowly by side wall. After filling the solution into the mold it is cured for 48 hours at room temperature. Care to be taken, so that water or moisture should not come into contact throughout the process in order to get proper final epoxy resin mold. Pouring epoxy resin into mold is shown in Fig. 5. Final molded epoxy resin sheet of thickness $6 \mathrm{~mm}$ is shown in Fig. 6.

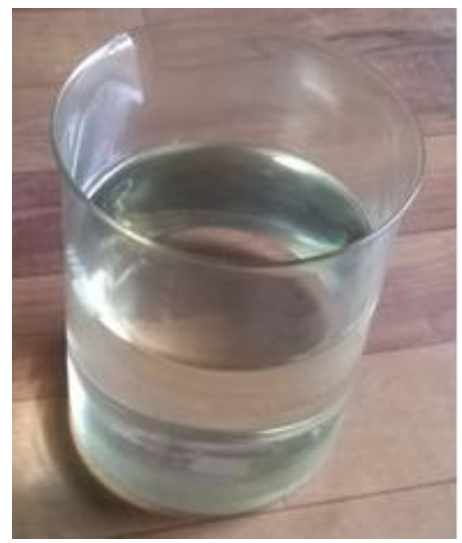

Fig.1 Beaker containing poured resin and hardener

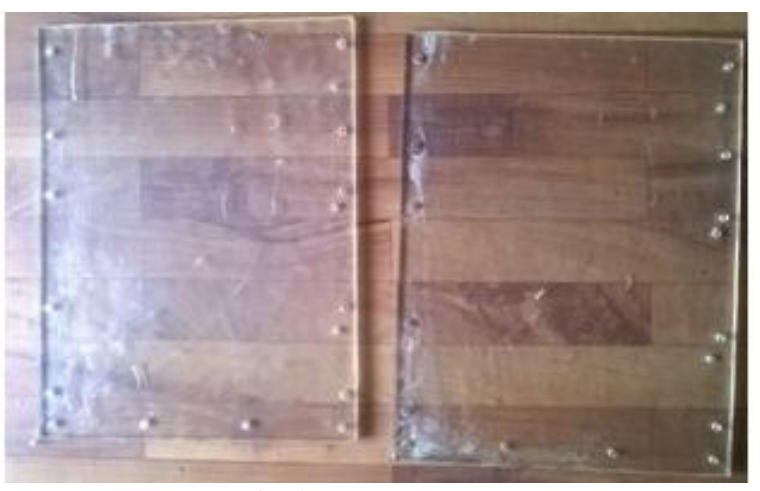

Fig.2 Perspex sheets

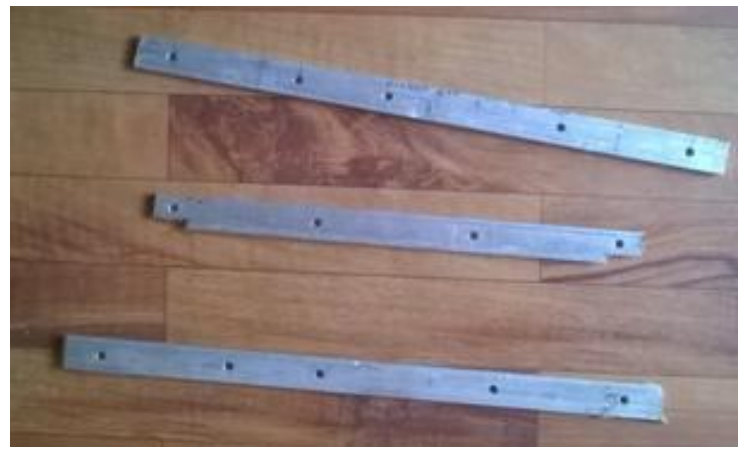

Fig.3 Aluminium spacers

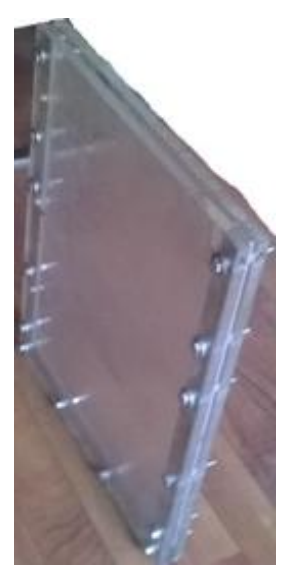

Fig. 4 Perspex mold 


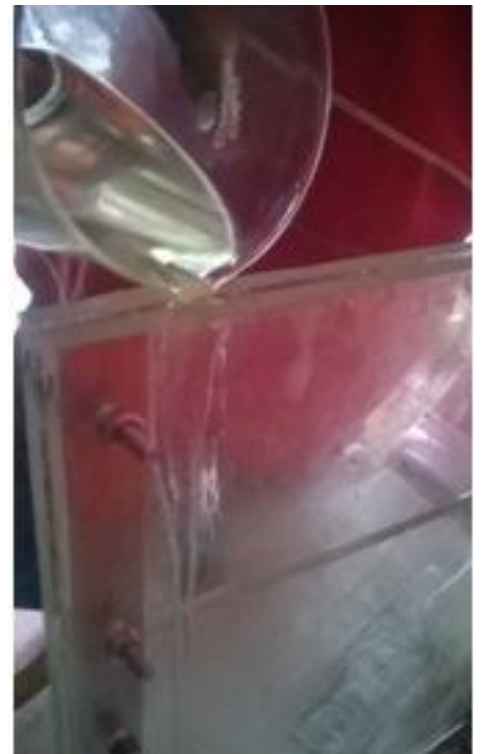

Fig.5 Pouring epoxy resin into the Perspex mold

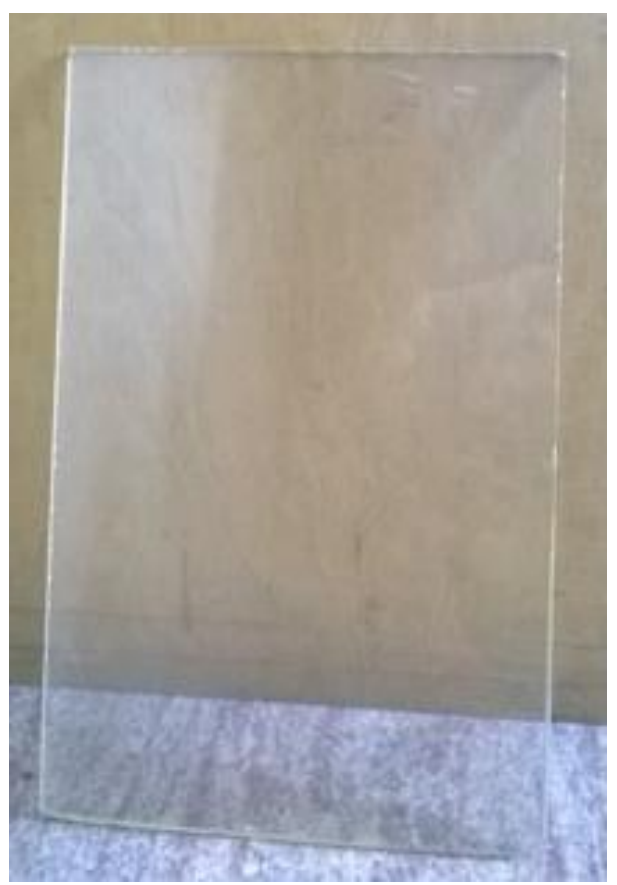

Fig. 6 Molded Epoxy resin sheet

\section{MACHINING AND CRACK INTRODUCTION}

\subsection{Machining Semi-Circular Disc}

The machined specimens by water jet machining are shown in Fig 7.

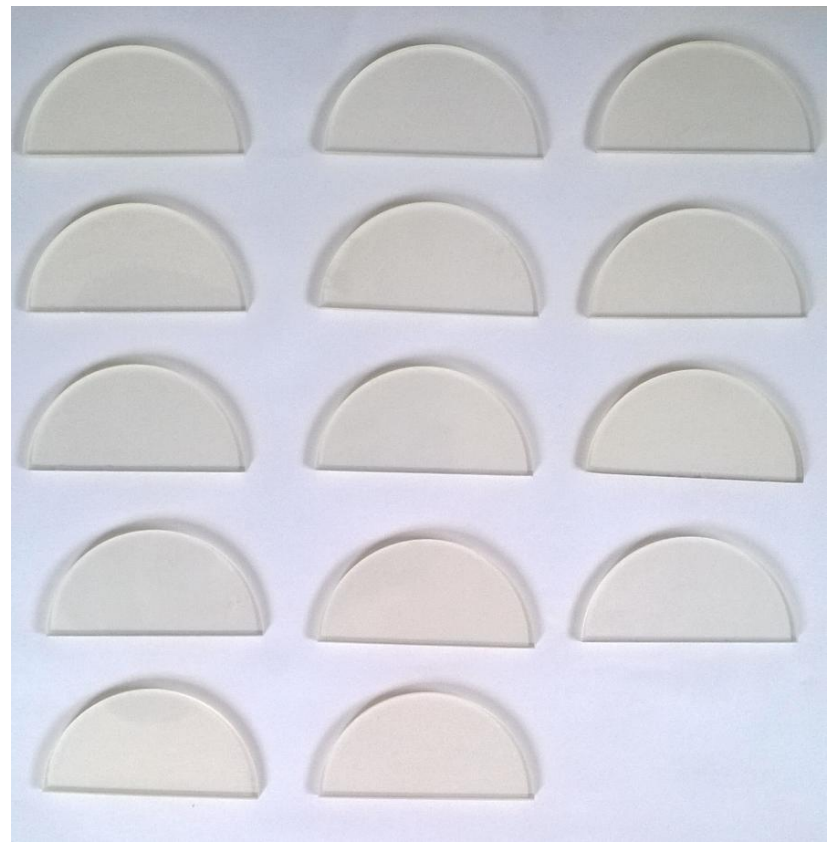

Fig. 7 Machined Specimens

Water jet machining is a Non Traditional Machining operation. This is used to machine or cut wide range of materials using pressurised water jet in combination with abrasive materials. Pure water jet machining is used to cut only soft materials. Addition of abrasive like silicon carbide, made the process versatile to machine wide range of materials including metals. From the molded Epoxy resin sheet, semi circular specimen is machined using Abrasive Water Jet Machining. Total number of specimens machined is 14 .

Each specimen has following dimensions:

Radius $(\mathrm{R})=60 \mathrm{~mm}$.

Thickness $(\mathrm{t})=6 \mathrm{~mm}$.

\subsection{Introduction of Crack}

Crack was introduced in the specimen using Tool and cutter machine. Tool and cutter machine is primarily used for resharpening of end mills, drill bits and variety of cutting tools.

Tool and cutter machine is shown in Fig. 7. Suitable disc fixture is attached to tool and cutter machine to create crack of $1.6 \mathrm{~mm}$ width. Crack introduced with disc fixture is shown in Fig 8. In 7 specimens $20 \mathrm{~mm}$ length crack is created and in remaining 7 specimens $30 \mathrm{~mm}$ length crack is created. Cracked specimens are shown in Fig 9 and Fig 10. 


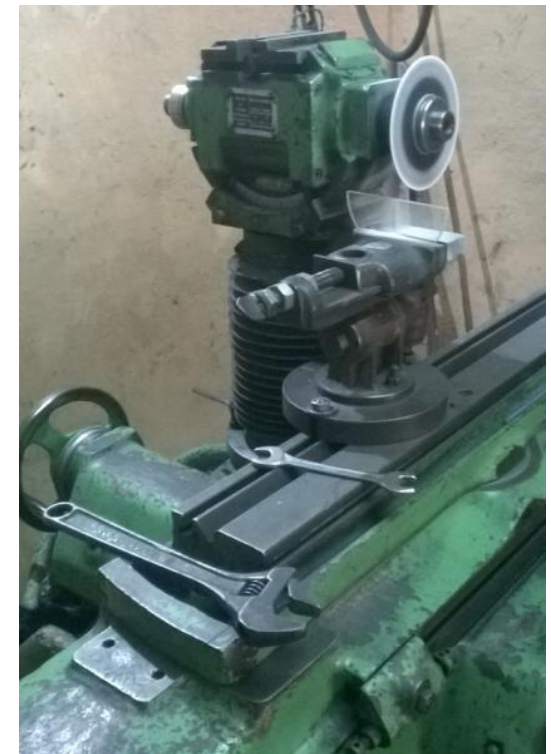

Fig. 8. Tool and cutter machine

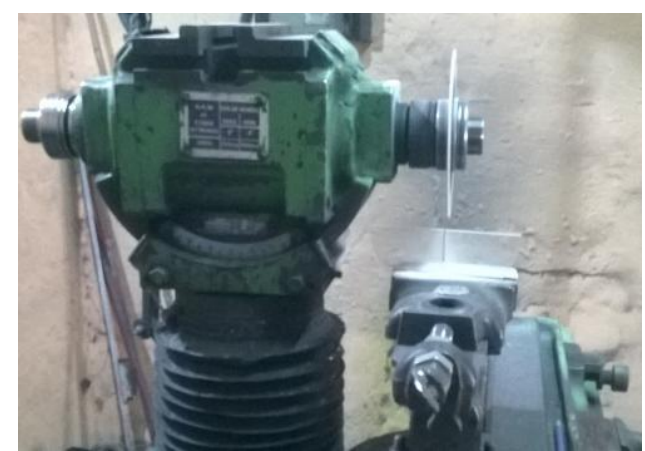

Fig. 9 Crack introduction on the Tool and cutter machine

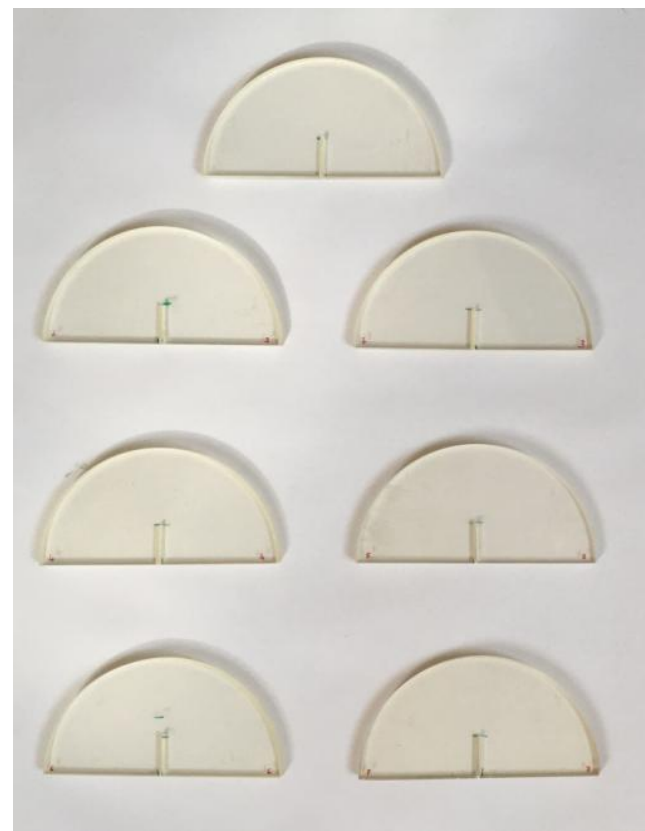

Fig.10. Specimens with $20 \mathrm{~mm}$ crack length

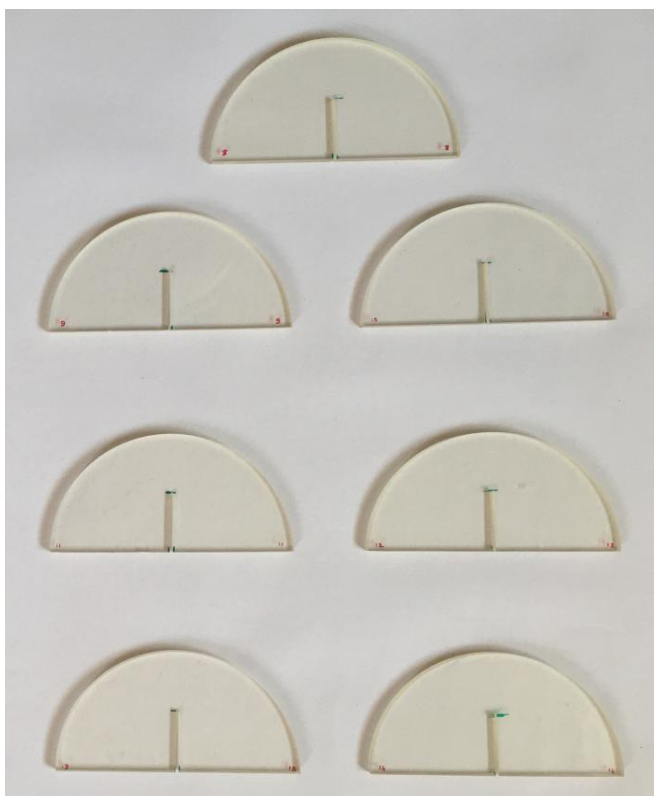

Fig. 11 Specimens with $30 \mathrm{~mm}$ crack length

\section{TESTING OF ASCB SPECIMENS}

The three point bending of Asymmetric Semi Circular Bend (ASCB) specimen was carried out on UNITEK-9550 series Universal testing machine. The main aim of the experiments is to find fracture loads and crack growth directions for different mixed mode combination.

\subsection{Universal Testing Machine}

The present work is carried out on Unitek 9550 special series Universal testing machine. It is shown in Fig.12. It is fully computer controlled. Controls are shown in Fig. 13.

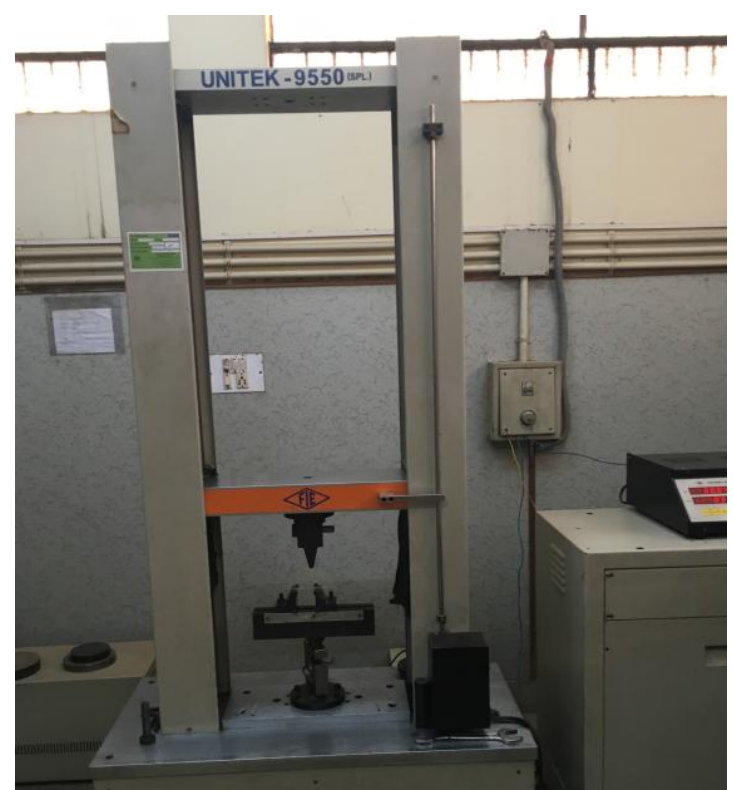

Fig. 12. Unitek-9550 Universal testing machine 


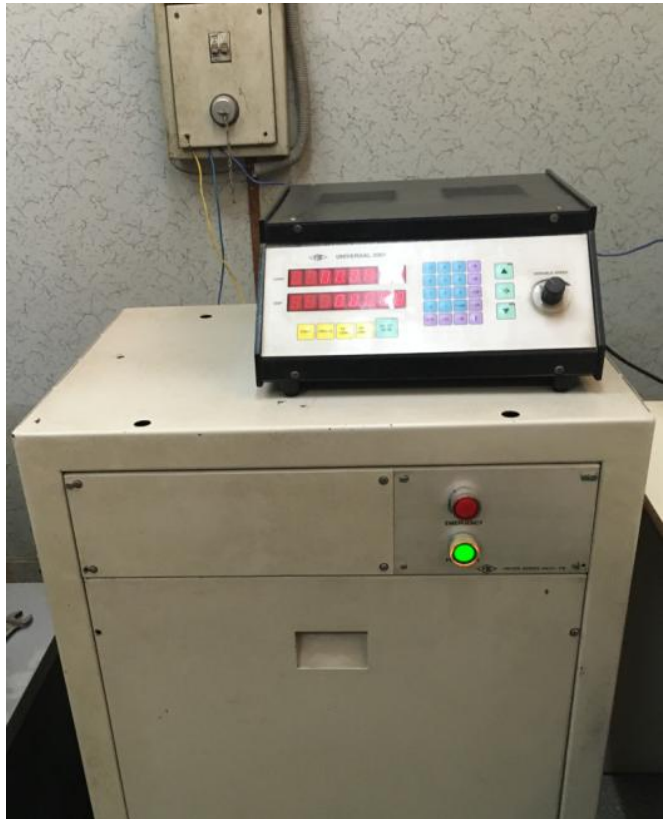

Fig. 13 Control Set-Up of UNITEK 9550 UTM

Testing of tensile and compressive strength of materials is generally done on universal tesing machine. Many standard tension and compression tests can be done on components, materials and structures. Hence the name universal associated with this machine. The present work is carried out on UNITEK 9550 special series Universal testing machine.

\subsection{Fixture for Asymmetric Bending Test}

The fixture needed for asymmetric bending test is shown in Fig 14. Its parts are Movable anvil, Curved crosshead nose, Lower anvil (2 Nos.), Screw to fix the lower anvil, Guide and scale. The 2 lower anvils can be set at any desired locations independently. So we can achieve different $\mathrm{S} 2$ values by moving and fixing right lower anvil to desired location.

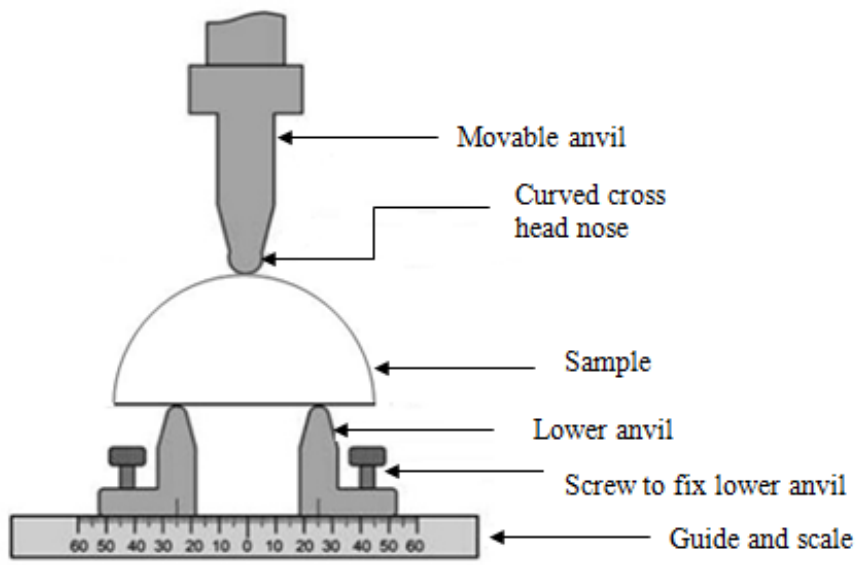

Fig. 14 Fixture
Then all specimens are located inside a loading fixture of three-point bend one by one for required values of S2 and S1. It is then loaded $1 \mathrm{~mm} / \mathrm{min}$ constant rate till specimen undergoes final fracture for each tests. Full computer controlled Universal testing machine (UTM machine) is employed for conducting 3 point bend test. The machine has a capacity of maximum load of $150 \mathrm{KN}$. The fracture load causing is recorded during all of the tests.

The details of the specimens during tests are tabulated in Table 1. Sl. No. 1-7 in the table is for $20 \mathrm{~mm}$ crack length specimens. S1. No. 8-14 in the table is for $30 \mathrm{~mm}$ crack length specimens. The values of S1, S2 for each test specimen to achieve pure mode I, full range of mixed mode conditions and pure mode $\mathbb{I}$ are mentioned in the table.

Here,

a - Crack length,

$\mathrm{R}$ - Radius of specimen, $(60 \mathrm{~mm})$

$\mathrm{S} 1$ - Distance of left lower anvil from vertical center position of specimen,

S2 - Distance of right lower anvil from vertical center position of specimen.

ASCB specimen geometry for pure mode-I fracture condition is shown in Fig.15 and for pure mode $\mathbb{I}$ it is shown in Fig.16. In all specimens thickness $(\mathrm{t})$ is $6 \mathrm{~mm}$ and Radius (R) is $60 \mathrm{~mm}$. The fixture with specimen in UTM during testing is shown in Fig. 17.

Table1: Specimen Details for Testing

\begin{tabular}{|l|l|l|}
\hline Sl. No. & $\begin{array}{l}\text { Crack length to } \\
\text { Radius }(\boldsymbol{a} / \mathrm{R}) \text { ratio }\end{array}$ & $\begin{array}{l}\text { Specimen Code } \\
\boldsymbol{X}-\boldsymbol{Y}: \boldsymbol{X}=\boldsymbol{S}_{\mathbf{I}}(\mathbf{m m}), \\
\boldsymbol{Y}=\boldsymbol{S}_{2}(\mathbf{m m})\end{array}$ \\
\hline 1 & $1 / 3$ & $40-6.07$ \\
\hline 2 & $1 / 3$ & $40-7.5$ \\
\hline 3 & $1 / 3$ & $40-9$ \\
\hline 4 & $1 / 3$ & $40-12$ \\
\hline 5 & $1 / 3$ & $40-15$ \\
\hline 6 & $1 / 3$ & $40-23$ \\
\hline 7 & $1 / 3$ & $40-40$ \\
\hline 8 & $1 / 2$ & $40-6.07$ \\
\hline 9 & $1 / 2$ & $40-7.5$ \\
\hline 10 & $1 / 2$ & $40-9$ \\
\hline 11 & $1 / 2$ & $40-12$ \\
\hline 12 & $1 / 2$ & $40-15$ \\
\hline 13 & $1 / 2$ & $40-23$ \\
\hline 14 & $1 / 2$ & $40-40$ \\
\hline
\end{tabular}

\subsection{Experimental Plan}

For all of the experiments the $\mathrm{S} 1$ distance was kept as $40 \mathrm{~mm}$. All range of I/II cases of mixed mode are covered by varying $\mathrm{S} 2$ values. $\mathrm{S} 2$ values taken for experiments in $\mathrm{mm}$ are: $\mathrm{S} 2=$ [40 (pure mode I), 23, 15, 12, 9, 7.5 and 6.07 (pure mode II)]. 


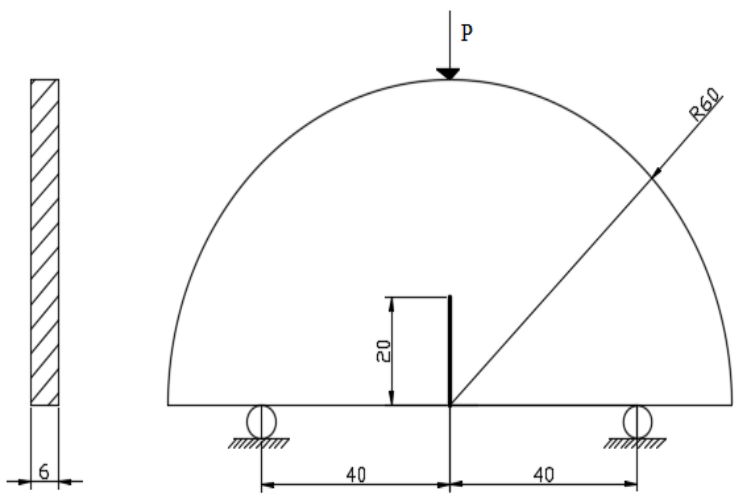

Fig.15. ASCB specimen geometry for pure mode-I condition with $\mathrm{a}=20 \mathrm{~mm}, \mathrm{~S} 1=40 \mathrm{~mm}, \mathrm{~S} 2=40 \mathrm{~mm}$

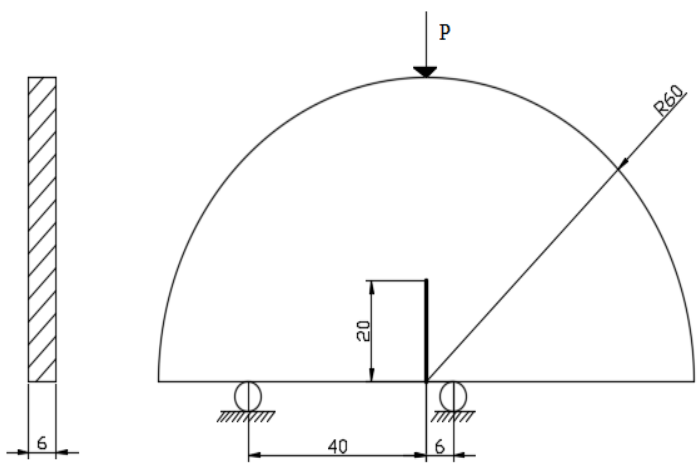

Fig.16. ASCB specimen geometry for pure mode-II condition with $\mathrm{a}=20 \mathrm{~mm}, \mathrm{~S} 1=40 \mathrm{~mm}, \mathrm{~S} 2=6.07 \mathrm{~mm}$

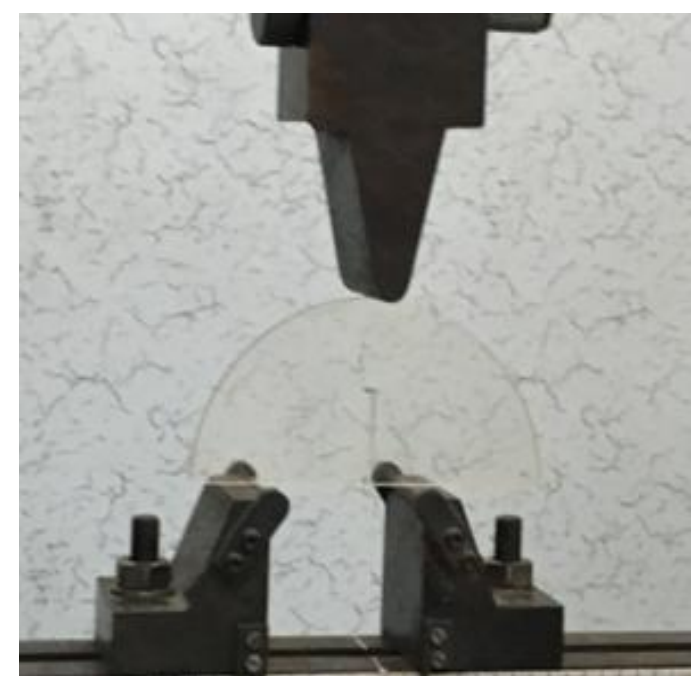

Fig.17. The fixture with specimen in UTM during testing

\section{RESULTS}

The outputs of the experiments are fracture loads and load vs Displacement curves. Also from the output broken samples we can measure fracture propagation directions. Statistical significant results can be generated from output data.

\subsection{Fracture Load}

The summary of the fracture load $\left(\mathrm{P}_{\mathrm{cr}}\right.$ obtained by mixed mode fracture tests on Epoxy resin ASCB specimens are listed in Table 2. Fractured specimens of crack length $20 \mathrm{~mm}$ is shown in Fig 18 and crack length $30 \mathrm{~mm}$ is shown in Fig 19.

Table 2: Specimen Details for Testing

\begin{tabular}{|l|l|l|l|}
\hline $\begin{array}{l}\text { Sl. } \\
\text { No. }\end{array}$ & $\begin{array}{l}\text { Crack length } \\
\text { to Radius }(\mathbf{a} / \mathbf{R}) \\
\text { ratio }\end{array}$ & Specimen code & $\begin{array}{l}\mathbf{P}_{\mathbf{c r}} \\
(\mathbf{K N})\end{array}$ \\
\hline 1 & $1 / 3$ & $\begin{array}{l}40-6.07 \quad \text { (pure } \\
\text { mode II ) }\end{array}$ & 6.08 \\
\hline 2 & $1 / 3$ & $40-7.5$ & 5.708 \\
\hline 3 & $1 / 3$ & $40-9$ & 6.115 \\
\hline 4 & $1 / 3$ & $40-12$ & 5.948 \\
\hline 5 & $1 / 3$ & $40-15$ & 5.253 \\
\hline 6 & $1 / 3$ & $40-23$ & 4.548 \\
\hline 7 & $1 / 3$ & $\begin{array}{l}40-40 \quad \text { (pure } \\
\text { mode I ) }\end{array}$ & 3.093 \\
\hline 8 & $1 / 2$ & $\begin{array}{l}40-6.07 \quad \text { (pure } \\
\text { mode II ) }\end{array}$ & 3.945 \\
\hline 9 & $1 / 2$ & $40-7.5$ & 4.783 \\
\hline 10 & $1 / 2$ & $40-9$ & 4.395 \\
\hline 11 & $1 / 2$ & $40-12$ & 4.17 \\
\hline 12 & $1 / 2$ & $40-15$ & 3.87 \\
\hline 13 & $1 / 2$ & $40-23$ & 3.473 \\
\hline 14 & $1 / 2$ & $\begin{array}{l}40-40 \quad \text { (pure } \\
\text { mode I ) }\end{array}$ & 1.985 \\
\hline & & \multicolumn{2}{|l}{} \\
\hline
\end{tabular}

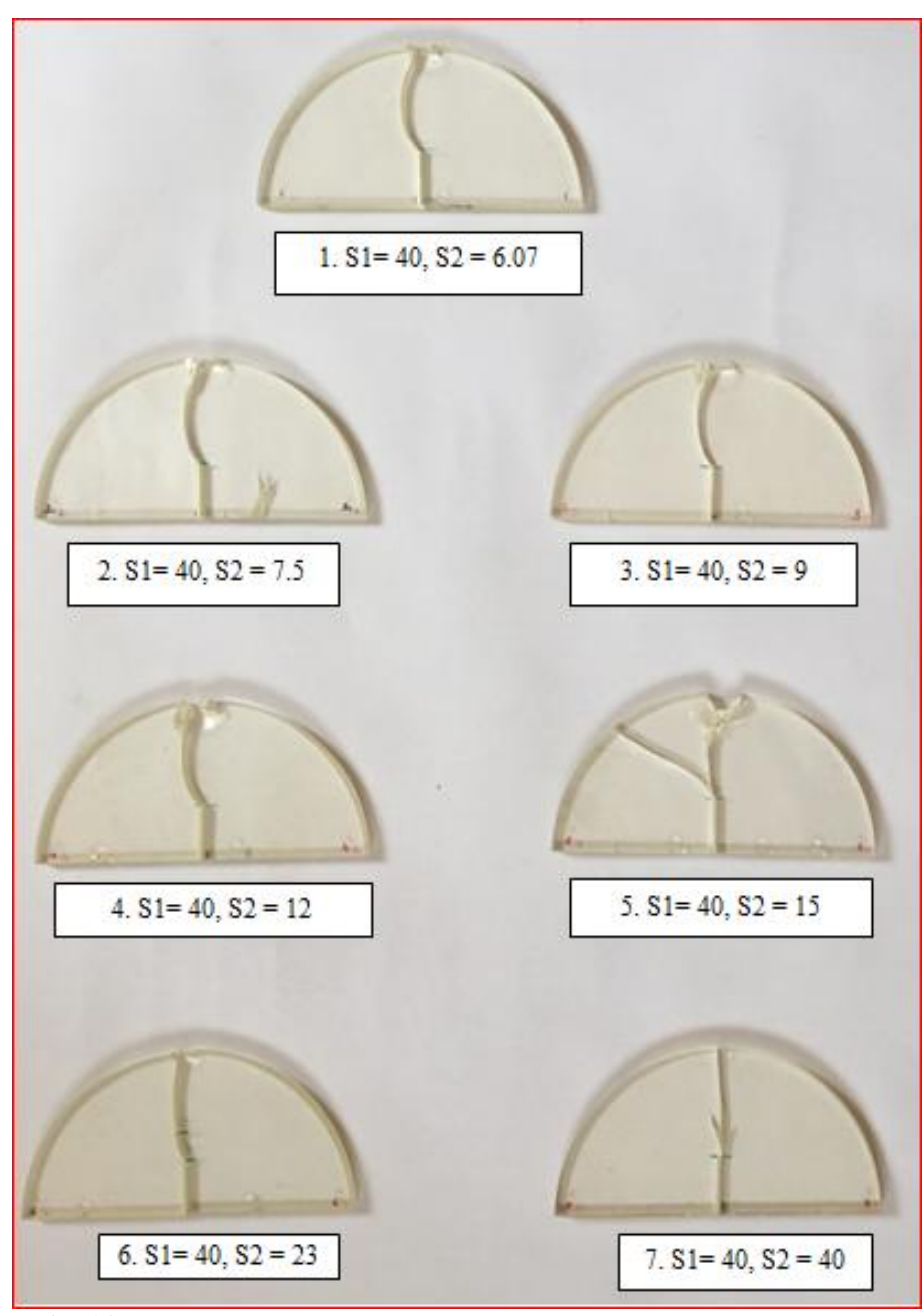

Fig.18. Fractured specimens having crack length (a) $20 \mathrm{~mm}$ 


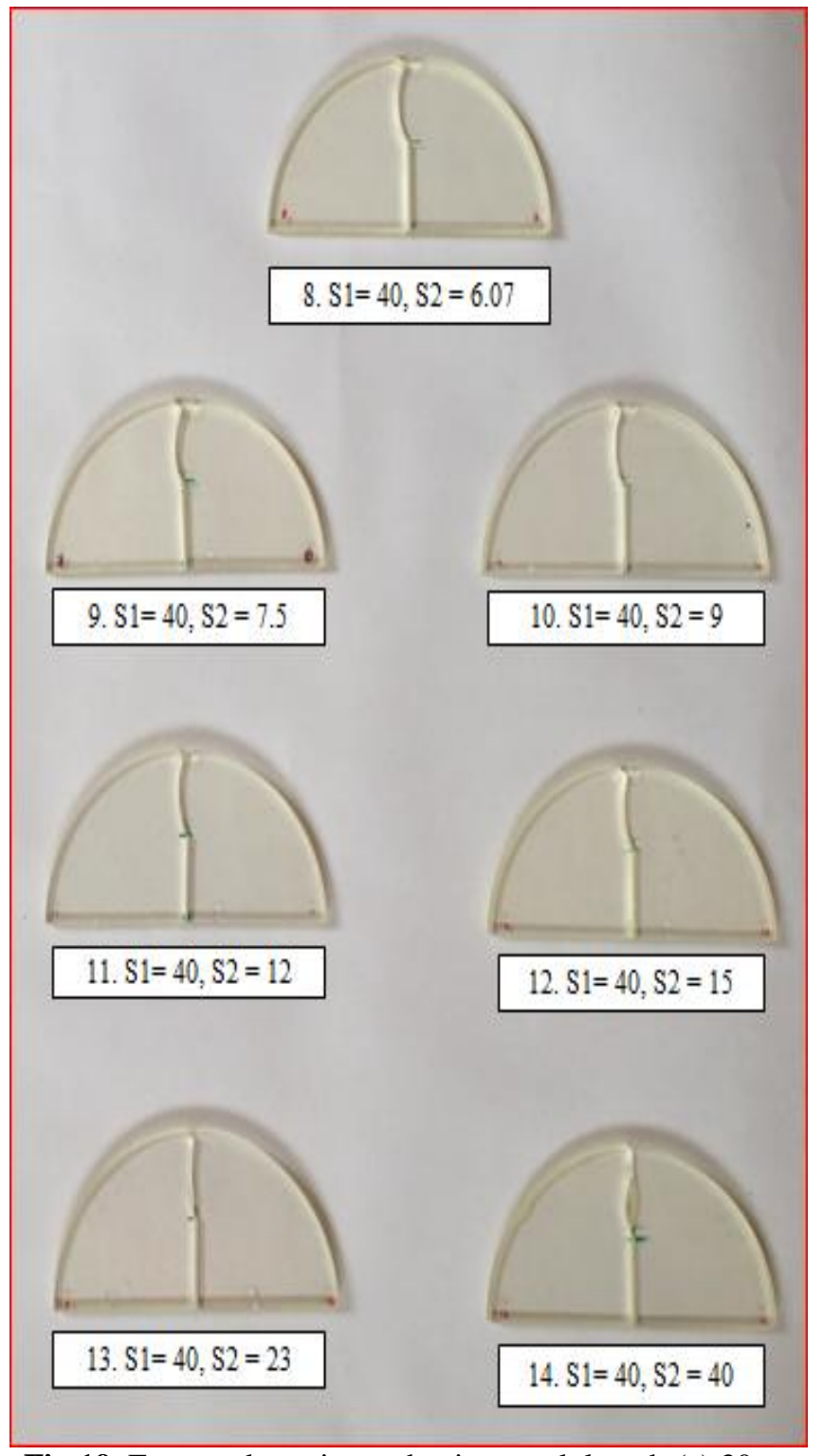

Fig.19. Fractured specimens having crack length (a) $30 \mathrm{~mm}$

\subsection{Crack Propagation Direction}

Crack propagation direction is given by angle $\theta_{c}$. It is the angle subtended by the vertical line drawn at crack tip with tangent drawn from crack tip to fracture curve. It is tabulated in Table 3.

Table 3: Crack Propagation direction

\begin{tabular}{|c|c|c|c|}
\hline $\begin{array}{l}\text { Sl. } \\
\text { No. }\end{array}$ & $\begin{array}{l}\text { Crack } \\
\text { length to } \\
\text { Radius } \\
(\mathrm{a} / \mathrm{R}) \text { ratio }\end{array}$ & Specimen code & $\begin{array}{l}\boldsymbol{\theta}_{\mathrm{c}} \\
\left({ }^{\circ}\right)\end{array}$ \\
\hline 1 & $1 / 3$ & $\begin{array}{l}40-6.07 \quad \text { (pure } \\
\text { mode II ) }\end{array}$ & 47 \\
\hline 2 & $1 / 3$ & $40-7.5$ & 41 \\
\hline 3 & $1 / 3$ & $40-9$ & 36 \\
\hline 4 & $1 / 3$ & $40-12$ & 33 \\
\hline 5 & $1 / 3$ & $40-15$ & 29 \\
\hline 6 & $1 / 3$ & $40-23$ & 20 \\
\hline 7 & $1 / 3$ & $40-40 \quad$ (pure & 0 \\
\hline
\end{tabular}

\begin{tabular}{|l|l|l|l|}
\hline & & mode I ) & \\
\hline 8 & $1 / 2$ & $\begin{array}{l}40-6.07 \quad \text { (pure } \\
\text { mode II ) }\end{array}$ & 39 \\
\hline 9 & $1 / 2$ & $40-7.5$ & 38 \\
\hline 10 & $1 / 2$ & $40-9$ & 37 \\
\hline 11 & $1 / 2$ & $40-12$ & 32 \\
\hline 12 & $1 / 2$ & $40-15$ & 29 \\
\hline 13 & $1 / 2$ & $40-23$ & 16 \\
\hline 14 & $1 / 2$ & $\begin{array}{l}40-40 \quad \text { (pure } \\
\text { mode I ) }\end{array}$ & 0 \\
\hline
\end{tabular}

\subsection{Load vs Displacement Curves}

One more output of the experiment is displacement or crosshead movement. So Load vs Displacement graphs are obtained as shown in this section. This is shown from Fig. 20-Fig.29.

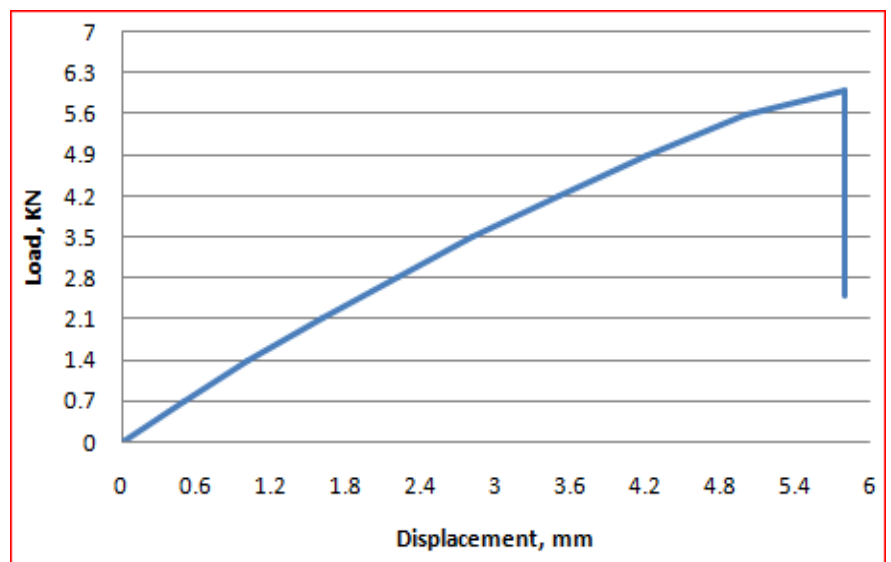

Fig.20 Load vs displacement graph for specimen $\mathrm{a}=20, \mathrm{~S} 1=$ $40, \mathrm{~S} 2=6.07$

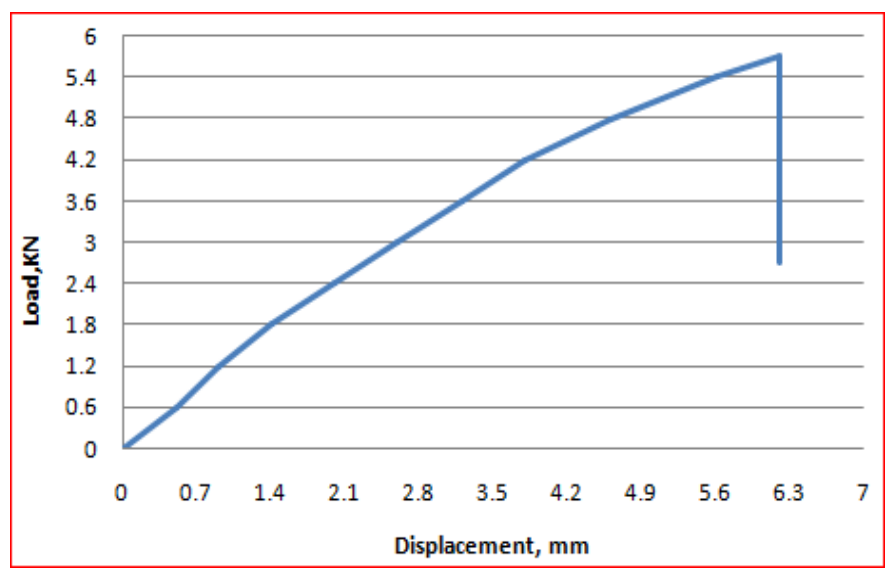

Fig.21 Load vs displacement graph for specimen $\mathrm{a}=20, \mathrm{~S} 1=$ $40, \mathrm{~S} 2=7.5$ 


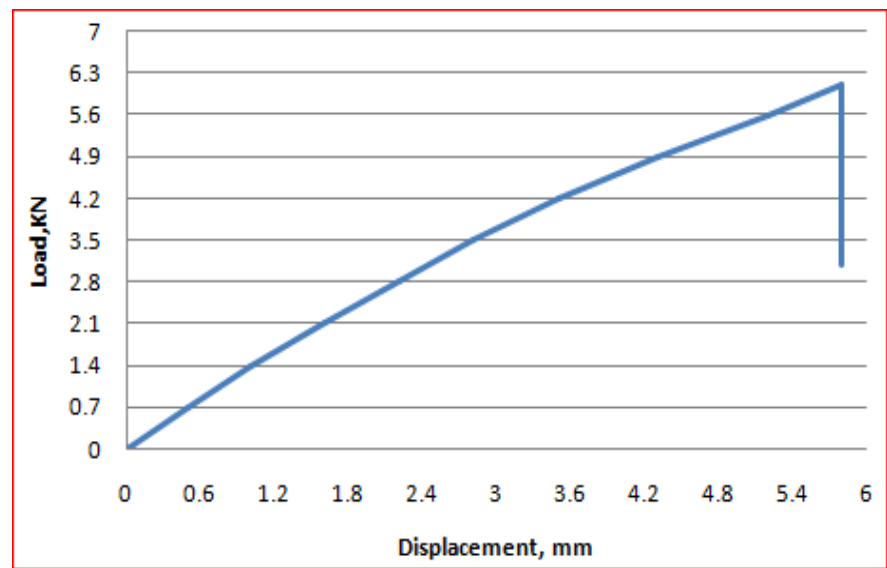

Fig.22 Load vs displacement graph for specimen a = 20, S1 = $40, \mathrm{~S} 2=9$

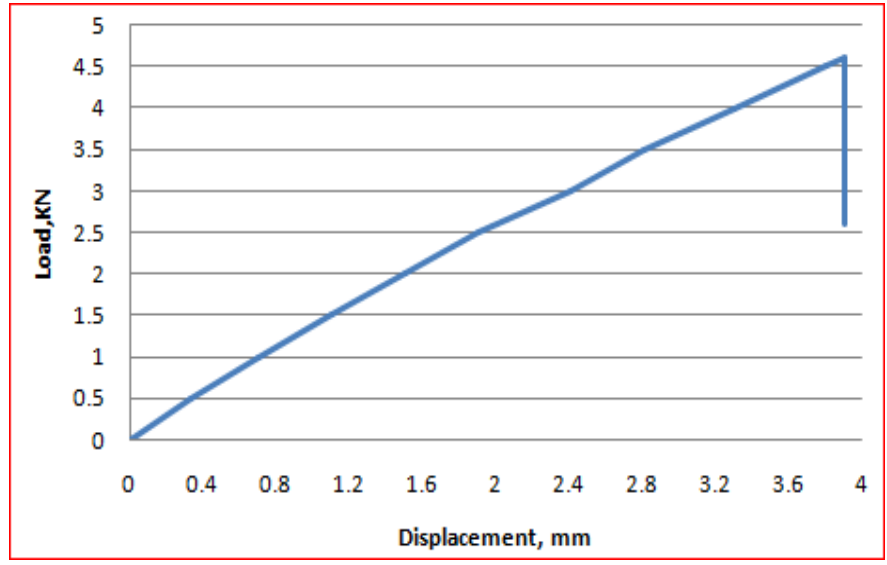

Fig.23 Load vs displacement graph for specimen $\mathrm{a}=20, \mathrm{~S} 1=$ $40, \mathrm{~S} 2=23$

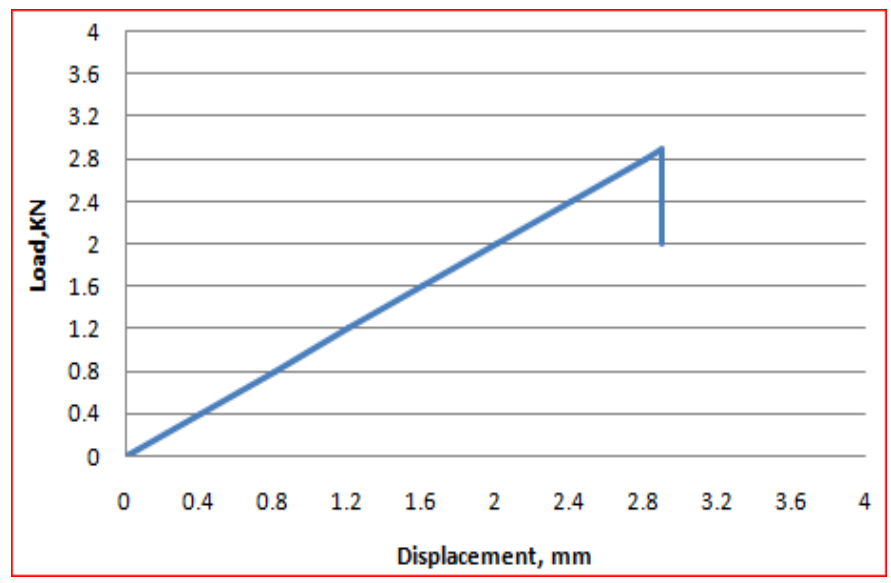

Fig.24 Load vs displacement graph for specimen a = 20, S1 = $40, \mathrm{~S} 2=40$

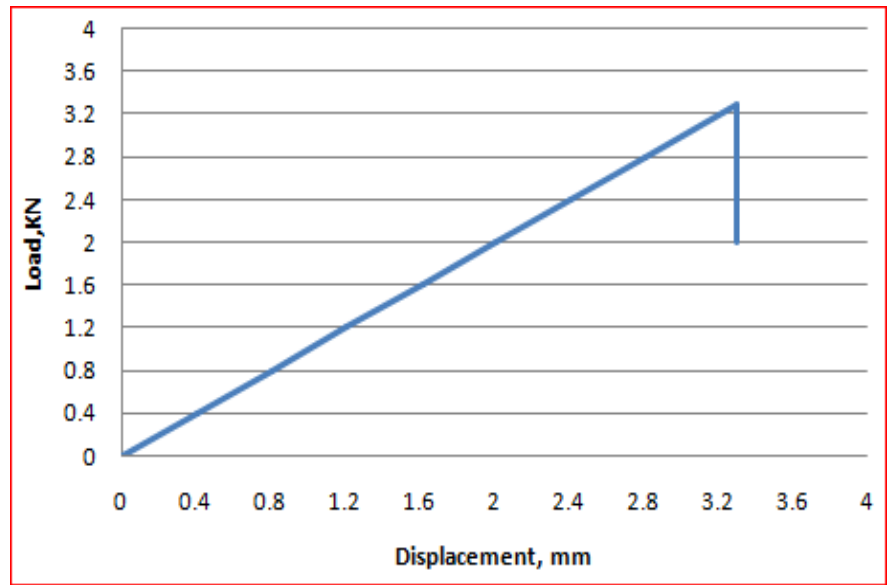

Fig.25 Load vs displacement graph for specimen a = 30, S1 = $40, \mathrm{~S} 2=6.07$

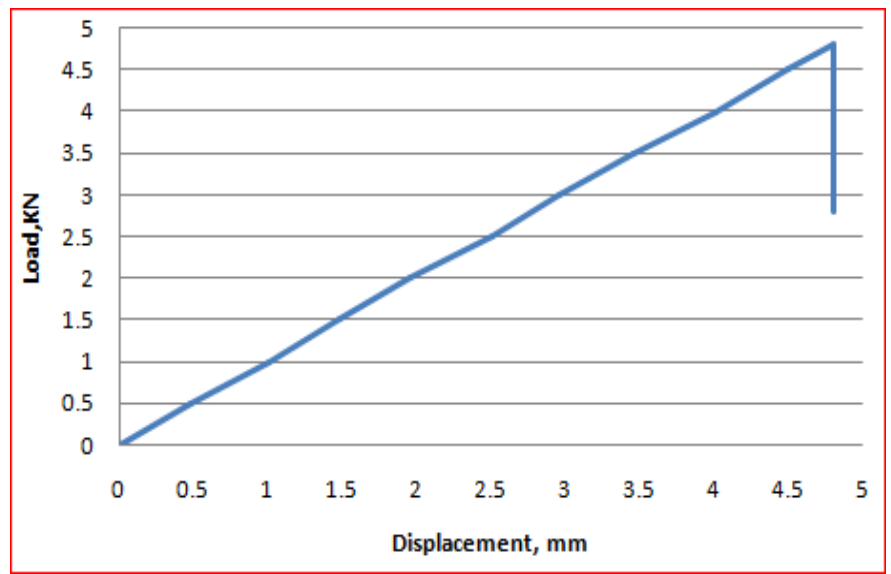

Fig.26 Load vs displacement graph for specimen $\mathrm{a}=30, \mathrm{~S} 1=$ $40, \mathrm{~S} 2=7.5$

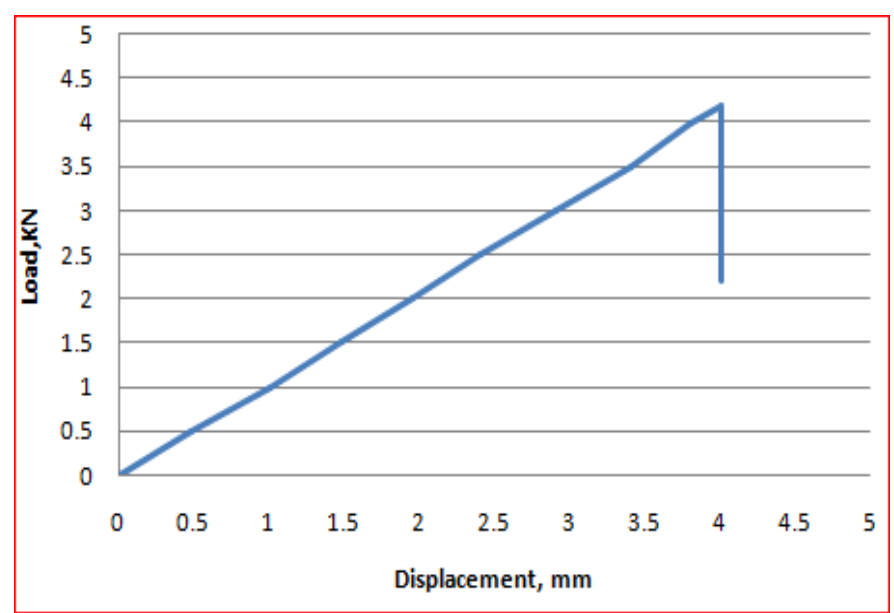

Fig.27 Load vs displacement graph for specimen $\mathrm{a}=30, \mathrm{~S} 1=$ $40, \mathrm{~S} 2=12$ 


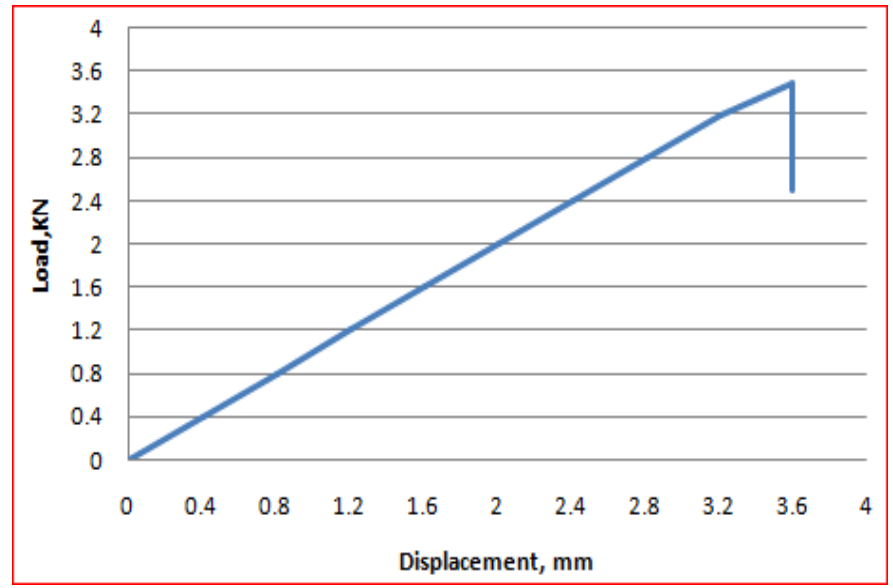

Fig.28 Load vs displacement graph for specimen $\mathrm{a}=30, \mathrm{~S} 1=$ $40, \mathrm{~S} 2=23$

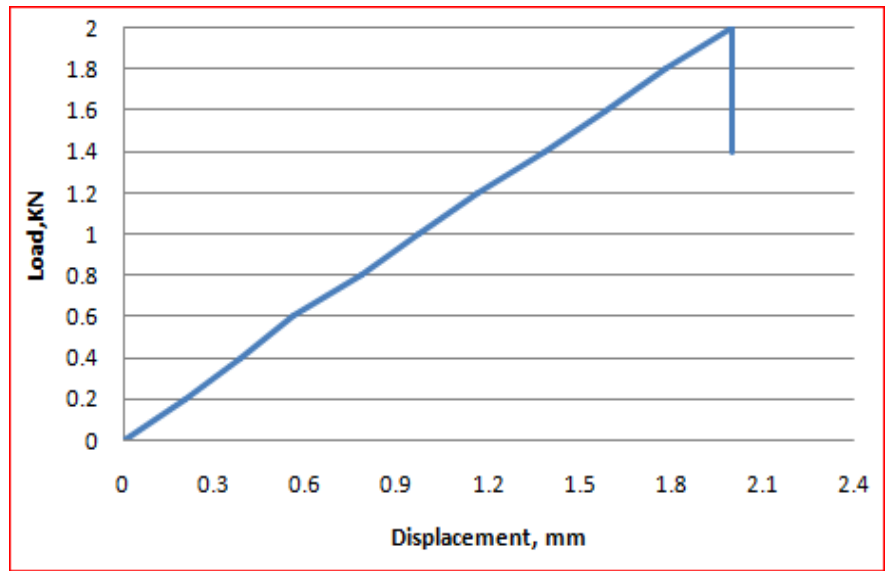

Fig.29 Load vs displacement graph for specimen $\mathrm{a}=30, \mathrm{~S} 1=$ $40, \mathrm{~S} 2=40$

\section{CONCLUSION}

1. ASCB test configuration is verified for conducting mixed mode I / I fracture tests on Brittle materials.

2. The simple test set up, simple geometry and simple fixtures are main advantages of ASCB specimens. Also crack creation is simpler.

3. The fracture load for fracture of Epoxy specimens is higher than PMMA. PMMA ASCB specimen testing work was done by Ayatollahi et al. [1]. This shows Epoxy resin is less brittle compared to PMMA.

4. Further using appropriate fracture criteria for mixed mode fracture, Fracture toughness can be calculated.

\section{REFERENCES}

[1] M. R. Ayatollahi, M. R. M. Aliha, H. Saghafi (2011), 'An improved semi-circular bend specimen for investigating mixed mode brittle fracture', Engineering Fracture Mechanics 78, pp. 110-123

[2] Erdogan F. and G.C. Sih (1963), 'On the crack extension in plates under plane loading and transverse shear', Journal of Basic Engineering, Transactions of ASME 85, pp. 519-525.
[3] G.C. Sih (1974), 'Strain-energy-density factor applied to mixed mode crack problems', International Journal of Fracture 10 (3), pp. 305-321.

[4] S.W. Freiman, A.C. Gonzalez, J.J. Mecholsky (1979), 'Mixed-mode fracture in soda-lime glass', Journal of the American Ceramic society 62 (3-4), pp. 206-208.

[5] D.K. Shetty, A.R. Rosenfield , W.H. Duckworth (1986), 'Mixed mode fracture of ceramics in diametral compression', Journal of the American Ceramic Society 69 (6), pp. 437-443.

[6] G.S. Glaesemann, J.E. Ritter, K. Jaku (1987), 'Mixedmode fracture in soda-lime glass using indentation flaws', Journal of the American Ceramic Society 70 (9), pp. 630-636.

[7] M.Y. He, H.C. Cao, A.G. Evans (1990), 'Mixed mode fracture: the four-point shear specimen', Acta Metallurgica et Materialia 38 (5), pp. 839-846.

[8] R. Dal Maschio, Lucio nobile (1994), 'A simplified approach for ceramic fracture toughness evaluation by indentation', Engineering fracture mechanics, Vol 51, No. 2, pp 209-215.

[9] L. Lim, W. Johnson, K. Choi, N. Boland (1994), 'Fracture testing of a soft rock with semi circular specimens under three-point bending. Part 2-mixed mode', Int. J. Rock Mech. Min. Sci. \& Geomech. Abstr. Vol. 31, No. 3, pp. 199-212.

[10] G. R. Krishnan, X. L. Zhao, M. Zaman, J.C. Roegiers (1997), 'Fracture toughness of a soft sandstone', Int. J. Rock Mech. Min. Sci. Vol. 35, No. 6, pp. 695-710.

[11] Hideo Awaji, T. Kato, S. Honda, T. Nishikawa (1999), 'Criterion for combined mode I-II brittle fracture', Journal of the Ceramic Society of Japan Vol. 107, No.10, pp. 918-924.

[12] K. Khan, N.A. Al-Shayea (2000), 'Effect of specimen geometry and testing method on mixed mode I - II fracture toughness of a limestone rock from Saudi Arabia', Rock Mech. Rock Engng. Vol 33. No. 3, pp.179-206.

[13] J.Gong, Y. Chen, C. Li (2001), 'Statistical analysis of fracture toughness of soda-lime glass determined by indentation', Journal of Non-Crystalline Solids 279, pp. 219-223.

[14] Soo-Ho Chang, chung-In Lee, seokwon Jeon (2002), 'Measurement of rock fracture toughness under modes I and II and mixed mode conditions by using disc-type specimens', Engineering geology 66, pp. 7997.

[15] M.R. Ayatollahi, M.R.M. Aliha (2006), 'On determination of mode II fracture toughness using semi-circular bend specimen', International Journal of Solids and Structures 43, pp. 5217-5227.

[16] M.R. Ayatollahi, M.R.M. Aliha, M.M. Hassani (2006), 'Mixed mode brittle fracture in PMMA- An experimental study using SCB specimens, Material science and Engineering A 417, pp. 348-356.

[17] A. Koike, M. Tomozawa, S. Ito (2007), 'Sub-critical crack growth rate of soda-lime-silicate glass and less brittle glass as a function of fictive temperature',Journal of Non-Crystalline Solids 353, pp. 2675-2680. 
[18] R. Hasanpour, N. Choupani (2008), 'Mixed mode study of rock fracture mechanics by using the modified arcan specimen test', International journal of mechanical, aerospace, industrial, mechatronic and manufacturing engineering, Vol.2, no.5, pp. 716-721.

[19] M.R. Ayatollahi, M.R.M. Aliha (2009), 'Mixed mode fracture in soda lime glass analyzed by using generalized MTS criterion', International Journal of Solids and Structures 46, pp. 311-321.

[20] M.R.M. Aliha, M.R. Ayatollahi (2011), 'Mixed mode I / II brittle fracture evaluation of marble using SCB specimen', Procedia engineering 10, pp. 311-318.

[21] M.R.M. Aliha, M.R. Ayatollahi (2012), 'Analysis of fracture initiation angle in some cracked ceramics using the generalized maximum tangential stress criterion', international journal of solids and structures 49, 1877-1883.

[22] K. V . N Surendra, K. R. Y. Simha (2013), 'Synthesis and application of weight function for edge cracked semicircular disk', Engineering Fracture Mechanics, pp. 61-79 